\title{
Simulasi Kesiapsiagaan Bencana Terpadu Antar Mahasiswa Program Studi Kesehatan Di Upn"Veteran" Jakarta Dengan Pendekatan Interprofessional Collaboration
}

\author{
Desak Nyoman sithi, Ani Widiastuti \\ Fakultas IImu Kesehatan, Universitas Pembangunan Nasional Veteran Jakarta \\ desaknyoman@upnvj.ac.id, ani.andrunaomi@gmail.com
}

\begin{abstract}
Abstrak
Bahwa Indonesia sebagai negara rawan bencana, merupakan julukan yang sangat tepat, karena sejatinya Indonesia tidak pernah lepas dari bencana. Hampir tiada hari tanpa bencana, semua jenis bencana terjadi di Indonesia, baik bencana alam, bencana non alam, maupun bencana social. Permasalahan yang dihadapi adalah kurangnya pemahaman, kesadaran dan ketrampilan masyarakat termasuk mahasiswa, terhadap antisipasi potensi resiko bencana, dampak bencana dan cara penanggulangan bencana. Atas dasar itu Pengabdi sebagai dosen pengampu mata kuliah Kesehatan Matra di Fikes UPN"Veteran" Jakarta tergerak untuk melakukan Pengabdian Masyarakat melalui Simulasi Kesiapsiagaan Bencana terpadu antar mahasiswa Fikes UPN Veteran Jakarta pendekatan Interprofessional Collaboration. Tujuan dari simulasi ini adalah untuk mempersiapkan mahasiswa Fikes UPN"Veteran" Jakarta memiliki kesadaran terhadap potensi resiko bencana sejak dini. Target yang ingin dicapai sebagai luaran dari pelatihan ini adalah mahasiswa memiliki kompetensi dalam mengantisipasi, mengurangi resiko dan dampak bencana serta memiliki ketrampilan dalam penanggulangan bencana, melalui pendekatan Interprofessional Collaboration. Metode yang diterapkan dalam simulasi ini adalah kombinasi beberapa pendekatan, mulai dari wawancara secara proporsional, pretest, pembekalan tentang Interprofesional Collaboration dalam penanggulangan bencana sesuai kompetensi dan profesinya masing-masing. Hasil yang dicapai dari simulasi ini menunjukkan terjadi peningkatan pengetahuan dan ketrampilan sebesar $67 \%$ dalam penanggulangan bencana dengan pendekatan Interprofessional Collaboration, terdiri dari: komunikasi, kerjasama, peran dan tanggung jawab, kolaborasi antar profesi, manajemen konflik, Fungsi Tim, leadership dan Pengorganisasian. Dari hasil wawancara terjadi perubahan perilaku kesiapsiagaan bencana dengan motto siap untuk selamat.
\end{abstract}

Kata Kunci: Kesiapsiagaan bencana, Simulasi, Interprofessional Collaboration,

\begin{abstract}
Indonesia is a disaster-prone country, in fact that Indonesia has never been free from disasters. Almost no day without a disaster, all types of disasters occur in Indonesia, both natural disasters, non-natural disasters, and social disasters. The problem is, lack of understanding, awareness and skills of the community, including students, to anticipate the potential of risk disaster, impact of disasters and disaster management. Based on above mention, we are lecturers at Health Sciences Faculty of UPN "Veteran" Jakarta, inspired to do Community Service through Disaster Preparedness Training by integrated Disaster Management Simulation with Interprofessional Collaboration approach between healthcare students of Health Sciences Faculty.The purpose of this training is to prepare all students of Health Sciences Faculty UPN "Veteran" Jakarta to be aware of the disaster http://ejournal.urindo.ac.id/index.php/PAMAS
\end{abstract}




\section{Jurnal Pelayanan dan Pengabdian Masyarakat (PAMAS)}

earlier. A movement is needed to change the culture and paradigm of the community to become aware of disasters, so that disaster preparedness training needs to be done regularly and continuously. The target to be achieved as an outcome of this training is students have competence in anticipating, reducing the risk and impact of disasters as well as having skills in disaster management. The method applied in this training is a combination of several approaches, ranging from proportional interviews, pre-tests, briefing on Interprofessional Collaboration in disaster management according to their respective competencies and professions, simulation of disaster management and ending with a post test for evaluation. The result achieved is an increase $67 \%$ in knowledge and skills in disaster management with the Interprofessional Collaboration approach, consisting of: communication, collaboration, roles and responsibilities, collaboration between professions, conflict management, Team Function, leadership and Organizing. Then the students were interviewed to evaluate their experience in disaster management and result of training and change in disaster preparedness behavior with a motto ready to survive.

Keywords: Disaster Preparedness, Interprofessional Collaboration, Resilien

\section{PENDAHULUAN}

Indonesia adalah Negara yang rawan terjadi bencana. Berbagai kejadian bencana alam yang telah terjadi mulai dari bencana alam, bencana non alam maupun bencana social. Antara lain gempa bumi, gunung meletus, tsunami, banjir, tanah longsor, angin putting beliung, wabah penyakit dan masih banyak lagi. Faktor utama penyebab banyaknya korban jiwa, dan dampak lain dari bencana adalah kurangnya pemahaman dan kesadaran masyarakat serta pelaku pengelola lingkungan terhadap risiko bencana di wilayahnya. Selain itu, kurangnya sosialisasi dan pelatihan untuk meningkatkan kesiapsiagaan terhadap bencana belum diberikan secara merata kepada masyarakat termasuk warga kampus. Hal ini mengakibatkan kurangnya kewaspadaan, dan kesiapsiagaan masyarakat dalam menghadapi bencana.

Kesiapsiagaan Bencana Berbasis Masyarakat (KBBM) atau Community Based Disaster Preparedness (CBDP) adalah program pemberdayaan kapasitas masyarakat untuk mengambil inisiatif dalam mengurangi dampak bencana yang terjadi di lingkungan tempat tinggalnya.

Menurut Ketua BNPB (2017), Trend bencana kedepan cenderung terus meningkat, diantaranya $92 \%$ adalah bencana hidrometeorologi. Peningkatan bencana disebabkan oleh faktor alam dan antropogenik. Faktor alam meliputi dampak perubahan iklim global dimana frekuensi hujan ekstrim makin meningkat dan kerentanan lingkungan. Sedangkan, 


\section{Jurnal Pelayanan dan Pengabdian Masyarakat (PAMAS)}

pengaruh antropogenik meliputi tingginya degradasi lingkungan, permukiman di daerah rawan bencana, DAS kritis, urbanisasi, dan lainnya.

Oleh karena itu bencana yang terjadi berturut-turut memperingatkan bangsa Indonesia untuk mempersiapkan masyarakat dan kota Tangguh Bencana. Hal ini diharapkan dapat mengendalikan dampak bencana terhadap berbagai aspek kehidupan mulai dari korban jiwa dan semua aspek kehidupan terutama kerusakan infrastruktur, meningkatnya kemiskinan, penurunan produktivitas tenaga kerja, serta mengancam ketahanan pangan nasional.

Berdasarkan kondisi diatas, perlu adanya gerakan untuk merubah budaya masyarakat, menjadi budaya dan paradigma sadar bencana, sehingga perlu dilakukan sosialisasi dan pelatihan, maupun simulasi kesiapsiagaan secara teratur dan berkelanjutan, untuk mengukur sejauh mana kesadaran, kewaspadaan, dan kesiapsiagaan masyarakat dalam menghadapi bencana. BNPB menginisiasi tanggal 26 April sebagai Hari Kesiapsiagaan Bencana Nasional (HKBN), yang bertujuan untuk membudayakan latihan secara terpadu, terencana dan berkesinambungan guna meningkatkan kesadaran, kewaspadaan dan kesiapsiagaan masyarakat menuju Indonesia Tangguh Bencana (Willem Rapangilei/ Ketua BNPB, 2017).

Oleh karena itu Kesiapsiagaan Bencana Berbasis Masyarakat, termasuk warga kampus sangat diperlukan untuk mengurangi resiko dan dampak bencana yang terjadi di lingkungan.

Perlu dikembangkan kolaborasi peran, melalui Interprofessional Collaboration (IPC), agar masyarakat dapat berpartisipasi dalam pengelolaan resiko bencana. Sinergitas dan penguatan kelembagaan masyarakat sangat diperlukan untuk mewujudkan kota berketahanan dan tangguh bencana dimasa yang akan datang. Kolaborasi antar profesi kesehatan merupakan satu upaya untuk meningkatkan mutu pelayanan kesehatan, termasuk dalam penanggulangan bencana. Keterlibatan team dari berbagai institusi maupun relawan dari masyarakat menuntut kesiapan dari masing-masing team dan pemahaman dasar dalam penanggulangan bencana. 


\section{Jurnal Pelayanan dan Pengabdian Masyarakat (PAMAS)}

Atas dasar itu Pengabdi sebagai dosen pengampu kesehatan Matra tergerak mempersiapkan seluruh mahasiswa untuk sadar bencana mulai sejak dini, memiliki kompetensi dalam mengantisipasi, mengurangi resiko dan dampak bencana serta memiliki ketrampilan dalam penanggulangan bencana. Kompetensi ini sebagai bentuk diimplementasikan Kesehatan Matra yang merupakan keunggulan Fikes UPN "Veteran" Jakarta sebagai institusi yang beridentitas Bela Negara. Ketrampilan ini dilatihkan dalam Simulasi penanggulangan bencana, yang dilaksanakan secara terpadu antar program studi di lingkungan Fikes UPN "Veteran Jakarta.

Kegiatan pengabdian masyarakat berupa pelatihan mahasiswa ini menggunakan pendekatan Interprofesional Collaboration (IPC) yang dikembangkan di Fikes UPN" Veteran" Jakarta melalui collaborasi antar mahasiswa dalam team. Program studi yang terlibat dalam simulasi yaitu: program studi ilmu Keperawatan, program studi profesi Ners, program studi ilmu kesehatan masyarakat, program studi ilmu Gizi dan D3 Keperawatan dan D3 Fisioterapi, semua mahasiswa bersinergi dan berkolaborasi melalui konsep Inter Profesional Collaboration, dengan tujuan untuk meningkatkan kemampuan mahasiswa dalam hal komunikasi, kerja sama, peran dan tanggung jawab, pendekatan kolaborasi untuk penanganan pasien dan keluarga, manajemen konflik, fungsi team, leadership dan pengorganisasian

\section{PERMASALAHAN MITRA}

Permasalahan yang dihadapi Mitra (Fikes UPN"Veteran" Jakarta) saat ini antara lain:

1. Mata Kuliah Kesehatan Matra di berikan di Fakultas ilmu Kesehatan dan Fakultas kedokteran UPN"Veteran" Jakarta, sebagai jabaran dari Bela Negara yang merupakan identitas UPN "Veteran" Jakarta.

2. Masing-masing program studi sudah mendapat materi Kesehatan matra sebagai unggulan dari fakultas kesehatan di lingkungan UPN"Veteran" Jakarta.

3. Materi yang diberikan sangat kompehensif meliputi: Matra darat, matra Laut, Matra Udara dan Kepolisian, dengan focus penanganan kedaruratan pada kondisi matra masing-masing matra termasuk DVI pada matra kepolisian. Namun kompetensi yang dicapai belum diimplementasikan ke dalam tatanan nyata pada situasi kebencanaan

4. Sejak 2014 pengabdi menginisiasi implementasi kesehatan matra dalam bentuk simulasi penanggulangan bencana untuk mencapai kompetensi dalam 


\section{Jurnal Pelayanan dan Pengabdian Masyarakat (PAMAS)}

penanggulangan bencana, mengantisipasi dan mengurangi Resiko bencana dilingkunagn masing-masing.

5. Oleh karena itu agar kompetensi mahasiswa dapat dimanfaatkan pada saat terjadi bencana, maka keberlangsungan kompetensi mahasiswa perlu tetap terjaga.

\section{TUJUAN}

Tujuan pengabdian masyarakat ini adalah untuk meningkatkan kompetensi mahasiswa dalam penanggulangan bencana, baik pengetahuan maupun ketrampilan dalam mengimplementasikan Interprofesional Collaboration dalam penanggulangan bencana secara terpadu.

Oleh karena itu bila pelatihan ini dilakukan dengan baik dan sungguh-sungguh, secara rutin, diikuti oleh seluruh mahasiswa kesehatan, maka kesiapsiagaan mahasiswa dalam penanggalangan bencana dapat terwujud, dan siap diterjunkan kapanpun dan dimanapun terjadi bencana.

\section{SOLUSI DAN TARGET LUARAN}

Solusi yang ditawarkan kepada Fikes UPN"Veteran" Jakarta dari program Pengabdian Masyarakat ini adalah meningkatkan kompetensi mahasiswa terkait kesiapsiagaan bencana, meliputi peningkatan pengetahuan, kemampuan dan ketrampilan mahasiswa dalam penanggulangan bencana. Solusi ini diperlukan agar seluruh sivitas akademika Fikes UPN"Veteran" Jakarta selalu siap bila terjadi bencana. Cluster Kesehatan dalam suatu bencana merupakan ujung tombak dari pengggulangan bencana, untuk menyelamatkan jiwa para korban. Kegiatan yang dapat dilakukan untuk mengatasi masalah ini adalah memberikan pelatihan tentang Kesiapsiagaan bencana agar selalu siap bila terjadi bencana, kegiatan pelatihan dilaksanakan selama satu minggu.

Luaran utama dari kegiatan ini adalah Ketrampilan mahasiswa dalam penanggulangan bencana. Target Luaran wajib kedua yang ingin dicapai adalah publikasi Artikel ilmiah pada jurnal yang ber ISSN atau Prosiding ber ISBN dari Seminar Nasional

\section{METODE PELAKSANAAN}

Kegiatan Pengabdian Masyarakat ini dilakukan dalam bentuk Pelatihan Kesiapsiagaan Bencana, yang diakhiri dengan Simulasi Penanggulangan Bencana Terpadu. Metode yang akan diterapkan untuk mencapai target program kemitraan ini adalah 
Jurnal Pelayanan dan Pengabdian Masyarakat (PAMAS)

kombinasi beberapa pendekatan mulai dari: Wawancara, pre-test, pembekalan, latihan dilapangan, simulasi, dan evaluasi

Adapun langkah-langkah dari kegiatan tersebut adalah sebagai berikut:

1. Pelatihan diawali dengan wawancara kepada para mahasiswa secara proporsional,

2. Melakukan pre-test terkait pengetahuan dan ketrampilan tentang penanggulangan bencana,

3. Selanjutnya dilakukan pembekalan dikelas selama 3 hari, dilanjutkan dengan latihan dilapangan selama 3 hari.

4. Setelah dianggap cukup latihan dilapangan, maka dilakukan Simulasi Penaggulangan Bencana secara terpadu dilapangan, melibatkan mahasiswa keperawatan, Kesehatan masyarakat, Gizi dan Fisioterapi.

5. Selesai Simulasi mahasiswa dilakukan wawancara kembali untuk evaluasi dan post test dengan menggunakan pertanyaan yang sama, untuk mengetahui respon mahasiswa sebagai hasil pelatihan dan perubahan perilaku dalam implementasi kesiapsiagaan bencana.

Dalam pelaksanaan Simulasi Penanggulangan Bencana ini pengabdi menggunakan beberapa media untuk membantu kegiatan Simulasi, antara lain InFokus, Loudspeaker, Video, untuk pembekalan di kelas. Selanjutnya Kuesioner, untuk pre-test, Instruktur/Pelatih, Tenda, Tandu, Veltbed, Tandu NR (Neil Robertson), Ambulance, alat kesehatan dan team untuk latihan dilapangan.

\section{PELAKSANAAN ABDIMAS DAN HASIL YANG DICAPAI}

\section{Kompetensi yang ingin dicapai adalah:}

1. Kesiapsiagaan bencana, agar selalu siap bila terjadi bencana dan mampu mengurangi Resiko bencana.

2. Ketrampilan khusus yang ingin dicapai adalah mahasiswa dapat mengimplementasikan ketrampilan kegawatdaruratan pada kondisi bencana.

\section{Strategi yang diterapkan untuk mencapai Keluaran :}

Setelah mengikuti simulasi bencana mahasiswa mampu : 


\section{Jurnal Pelayanan dan Pengabdian Masyarakat (PAMAS)}

1. Melakukan pengkajian kegawat daruratan prehospital dengan menggunakan prinsip penanganan airway, breathing, dan circulation, baik di TKP maupun di posko kesehatan.

2. Melakukan Triase pada kasus-kasus kegawatdaruratan dan triage pada saat bencana

3. Melakukan tindakan kegawatdaruratan yang diperlukan di TKP.

4. Melakukan evakuasi dari TKP, ke posko kesehatan.

5. Melakukan pengkajian dan menetapkan diagnosa medis dan keperawatan ulang di posko kesehatan.

6. Melakukan tindakan sesuai kebutuhan.

7. Menyiapkan posko informasi, posko Post Mortem dan Ante Mortem.

8. Menyiapkan Dapur Umum

9. Melakukan Surveilance

10. Menyiapkan Posko Pengungsi

11. Melakukan evakuasi ke RS rujukan melalui ambulance.

12. Melakukan komunikasi efektif, antar Profesional Pemberi Asuhan (PPA), korban dan keluarganya

13. Memegang teguh standar profesi dalam pemberian asuhan tanpa mengabaikan etik dan legalitas walaupun pada situasi bencana.

\section{Waktu dan Tempat Penyelenggaraan}

Kegiatan simulasi dilaksanakan selama satu minggu dengan rincian kegiatan sebagai berikut:

1. Hari I sd III: kegiatan di kelas untuk pembekalan.

2. Hari IV : gladi kotor dan menyiapkan properti

Tempat : Lapangan Kampus Limo

3. Hari V : gladi bersih

Tempat : Lapangan Kampus Limo

4. Hari $\mathrm{H}$ pelaksanaan simulasi penanggulangan bencana terpadu.

\section{Peserta}

Peserta simulasi adalah Mahasiswa S1 Keperawatan, D3 Keperawatan, mahasiswa S1 Gizi dan mahasiswa S1 Kesehatan Masyarakat dengan jumlah 246 orang dengan rincian

1. S1 Keperawatan sebanyak 110 orang 2. 


\section{Jurnal Pelayanan dan Pengabdian Masyarakat (PAMAS)}

2. D3 Keperawatan 26 orang

3. S1 Ilmu Gizi 48 orang

4. S1 Kesehatan Masyarakat 63 orang

\section{HASIL YANG DICAPAI}

Selama Simulasi, mahasiswa yang berjumlah 246 orang, terdiri dari 4 program studi, menunjukkan semangat yang tinggi dan aktif mengikuti proses pelatihan. Mulai dari pembekalan materi, hingga kegiatan latihan dan simulasi di kampus II Fikes UPN"Veteran" Jakarta .

Adapaun gambaran peserta simulasi kesiapsiagaan bencana terpadu antar mahasiswa Fikes UPN"Veteran" Jakarta, adalah sebagai berikut:

\section{Tabel 1: Distribusi Responden Berdasarkan Program Studi}

\begin{tabular}{lcc}
\hline Program Studi & $\begin{array}{c}\text { Jumlah } \\
\text { (orang) }\end{array}$ & Prosentase \\
\hline S1 Keperawatan & 110 & $45 \%$ \\
D3 Keperawatan & 26 & $10 \%$ \\
S1 Gizi & 48 & $20 \%$ \\
S1 Kesehatan & 63 & $25 \%$ \\
Masyarakat & & \\
\hline Total & 246 & $100 \%$ \\
\hline
\end{tabular}

Dari 246 mahasiswa yang mengikuti kegiatan simulasi penanggulangan bencana terdistribusi dalam 4 program studi, dengan jumalah peserta terbanyak dari S1 Kepwrawatan sebanyak 45\% dan Kesehatan Masyarakat 25\%, sisanya S1 Gizi 25\% dan D3 Keperawatan $10 \%$.

2. Distriusi rata-rata Hasil Pre test sebelum Simulasi Penanggulangan Bencana Terpadu

\begin{tabular}{|l|c|c|c|c|c|c|}
\hline Komponen & $\mathbf{~ N}$ & Mean & Min & Max & Mean & Std Dev \\
\hline Komunikasi & 246 & 11.9 & 3 & 17 & 11.9 & 1.873 \\
\hline Kerjasama & 246 & 20.6 & 8 & 32 & 20.6 & 3.106 \\
\hline Kolaborasi & 246 & 7.64 & 4 & 12 & 7.64 & 1.134 \\
\hline $\begin{array}{l}\text { Manajemen } \\
\text { Konflik }\end{array}$ & 246 & 9.36 & 5 & 16 & 9.36 & 0.873 \\
\hline Fungsi Teamwork & 246 & 7.52 & 3 & 12 & 7.52 & 0.542 \\
\hline Leadership & 246 & 5.4 & 3 & 9 & 2.32 & 1.021 \\
\hline pengorganisasian & 246 & 6.11 & 4 & 16 & 6.11 & 0.923 \\
\hline
\end{tabular}




\section{Jurnal Pelayanan dan Pengabdian Masyarakat (PAMAS)}

Hasil pre test menunjukan dari 246 orang peserta simulasi, didapatkan hampir seluruh komponen dari Interprofessional Collaboration dengan nilai kurang dari 50\% dari score max. Hal ini menunjukkan perlunya upaya peningkatan pengetahuan dan ketrampilan terkait kesiapsiagaan bencana dengan pendekatan Interprofessional Collaboration.

3. Tabel 3. Distriusi rata-rata Hasil Post test setelah Simulasi Penanggulangan Bencana Terpadu

\begin{tabular}{|c|c|c|c|c|c|c|c|}
\hline Komponen & ! & .lean & .Iin & .las & . Neall & Std Der & Prosentase \\
\hline Komunitasi & 246 & 17.96 & 6 & 24 & 17.96 & 2.283 & $90 \%$ \\
\hline Kerjazama & 246 & 33.6 & 11 & 44 & 33.6 & 4.002 & $76.4 \%$ \\
\hline Koldorasis & 246 & 11.98 & 4 & 16 & 11.98 & 1911 & $73 \%$ \\
\hline Nerariemene Konfili & 246 & 14.76 & 5 & 20 & 14.76 & 1.671 & $73.8 \%$ \\
\hline Fungsil Temrintork & 246 & 12.57 & 4 & 16 & 12.57 & 1.845 & $78.5 \%$ \\
\hline Leadership & 246 & 9.37 & 3 & 12 & 9.37 & 1.458 & $77.2 \%$ \\
\hline pengorgegainasian & 246 & 12.11 & 4 & 16 & 12.11 & 1.858 & $76 \%$ \\
\hline
\end{tabular}

Dari hasil post test yang dilakukan setelah mengikuti rangkaian kegiatan pemberian materi pelatihan kesiapsiagaan bencana sampai dengan simulasi penanggulangan bencana, didapatkan bahwa peserta telah memiliki pemahaman dan ketrampilan yang baik tentang implementasi Interprofesional Collaboration dalam simulasi penanggulangan bencana dengan pencapaian nilai post test tertinggi mencapai $90 \%$ untuk komunikasi dan score terendah mencapai $73.8 \%$ untuk manajemen konflik serta rata-rata pencapaian score $78.3 \%$, diatas nilai batas lulus untuk post test (75\%).

4. Tabel 4. Distribusi rata-rata Hasil selisih pre dan Post test Simulasi Penanggulangan Bencana Terpadu

\begin{tabular}{|l|c|c|c|c|c|}
\hline Komponen & N & Pre & Post & selisih & $\begin{array}{c}\text { Growth } \\
\%\end{array}$ \\
\hline Komunikasi & 246 & 11.9 & 17.96 & 6.06 & $51 \%$ \\
\hline Kerjasama & 246 & 20.6 & 33.6 & 13 & $63 \%$ \\
\hline $\begin{array}{l}\text { Kolaborasi } \\
\text { Konflikemen }\end{array}$ & 246 & 7.64 & 11.98 & 4.34 & $57 \%$ \\
\hline Fungsi Teamwork & 246 & 7.52 & 12.57 & 5.05 & $67 \%$ \\
\hline Leadership & 246 & 5.4 & 9.37 & 3.97 & $74 \%$ \\
\hline $\begin{array}{l}\text { Lpengorganisasian } \\
\text { I- }\end{array}$ & 246 & 6.11 & 12.11 & 6 & $98 \%$ \\
\hline
\end{tabular}


Jurnal Pelayanan dan Pengabdian Masyarakat (PAMAS)

Dari table4 diatas menunjukkan terdapat peningkatan yang signifikan terhadap semua komponen Interprofessional Collaboration, dengan rata-rata peningkatan hasil pre dan post test adalah sebesar $67 \%$.

\section{PENUTUP}

Simulasi Kesiapsiagaan Bencana Terpadu antar mahasiswa Fikes UPN Veteran Jakarta, berjalan dengan baik, diikuti oleh 246 mahasiswa. Masing-masing mahasiswa berperan sesuai profesinya. Pengembangan kolaborasi peran perlu terus dikembangkan, agar masyarakat termasuk mahasiswa dapat berpartisipasi dalam identifikasi resiko bencana dalam mewujudkan kampus tangguh bencana.

Melalui pengabdian masayarakat dalam bentuk simulasi bencana terpadu pada mahasiswa fakultas ilmu kesehatan ini, mahasiswa dilibatkan dan dipersiapkan agar memiliki kemampuan untuk berbertahan diri, mendapat pembekalan kebencanaan, dan melakukan simulasi secara berkala berdasarkan standar operasional prosedur pengurangan risiko bencana dan upaya antisipatif mitigasi bencana yang disiapkan pemerintah. Membentuk dan memperkuat kelembagaan masyarakat dan instansi terkait penanganan kebencanaan, sehingga Sinergi menjadi pembelajaran untuk mendukung perwujudan kota berketahanan dimasa yang akan datang.

Interprofesional collaboration menjadi metode yang efektif dalam upaya mewujudkan Indonesia tangguh menghadapi bencana, Disamping pentingnya memiliki kapasitas termasuk kapasitas dalam bidang teknologi sangat penting adalah ada kolaborasi kerjasama antar semua stakeholder dan awareness masyarakat yang terus dibangun.

Pengabdian Masyarakat berupa pelatihan dan simulasi secara terpadu bagi mahasiswa Fakultas ilmu kesehatan bermanfaat untuk mempersiapkan kompetensi mahasiswa dalam kesiapsiagaan bencana, sehingga selalu siap bila terjadi bencana dan mengurangi Resiko akibat bencana.

\section{DAFTAR PUSTAKA}

Badan Penanggulanagn Bencana Nasional Edisi th 2017, Buku Saku Tanggap, Tangkas dan Tangguh Menghadapi Bencana. 
Jurnal Pelayanan dan Pengabdian Masyarakat (PAMAS)

Badan Nasional Penanggulangan Bencana. Pedoman Simulasi/Gladi Kesiapsiagaan Masyarakat Menghadapi Ancaman Gempa dan Tsunami, 2014 Badan Nasional Penanggulangan Bencana. Peraturan Kepala Badan Nasional Penanggulangan Bencana Tentang Rambu dan Papan Informasi Bencana, 2015.

Badan Nasional Penanggulangan Bencana. Risiko Bencana Indonesia. Jakarta: BNPB: 2016 20 Collaborarative Learning Tips and Strategis For Teachers, https://www.teachthought.com/wp-content/uploads/2018/05/20-collaborativelearning-tips.png.

HOPE Worldwide Indonesia. Panduan Guru Dalam Pengajaran Pengurangan Risiko Bencana (PRB), 2009

Kompas.com, 2018,: "Kolaborasi Dalam Mewujudkan Kota Tangguh Bencana", https://biz.kompas.com/read/2018/12/03/093058828/kolaborasi-dalam-mewujudkankota-tangguh-bencana

Marjan Laal, Seyed Mohammad Ghodsi, 2011 : Benefits of collaborative learning, 2011 Published by Elsevier Ltd.

Suyoso, Juli Astono, Dadan Rosana, 2009: Model Kesiapsiagaan Bencana (Disaster Preparedness) dalam Bentuk Pembelajaran Sekolah Darurat Dengan Pendekatan Fun Learning Menggunakan Media Pembelajaran Dari Limbah Rumah Tangga Untuk Penanganan Pendidikan Di Daerah Pasca Bencana, Prosiding Seminar Nasional Penelitian, Pendidikan dan Penerapan MIPA,Fakultas MIPA, Universitas Negeri Yogyakarta, 16 Mei 2009.

Pusat Kurikulum Badan Penelitian dan Pengembangan Kementerian Pendidikan Nasional. Modul Ajar Pengurangan Risiko Bencana Kebakaran. Jakarta: Kemdiknas 2009

Pusat Kurikulum Badan Penelitian dan Pengembangan Kementerian Pendidikan Nasional. Modul Ajar Pengurangan Risiko Bencana Longsor. Jakarta: Kemdiknas 2009

Supartini, E. dkk., 2017: Buku Pedoman Latihan Kesiapsiagaan Bencana : membangun Kesadaran, Kewaspadaan dan Kewaspadaan Menghadapi Bencana. Badan Penanggulanagn Bencana Nasional, Jakarta, 2017.

Supari, F. 2007: Panduan bagi Petugas Kesehatan Yang Bekerja dalam Penangan Krisis Kesehatan Akibat Bencana di Indonesia. Pusat Penanggulangan Krisis, Departemen Kesehatan R.I, Jakarta 2007 
Jurnal Pelayanan dan Pengabdian Masyarakat (PAMAS)

Shulman, D., Dringus, L. (2011). B-AWARE: Awareness Systems for Enhancing Virtual Team Presence in Online Learning Environments. $17^{\text {th }}$ Annual Sloan Consortium International Conference on Online Learning, Florida, November 2011.

S. Mackintosh,1 D. Mcclure2, 2018. Interprofessional Education as a Vehicle to Instill Teamwork Mentality for Disaster Preparedness and Response in Healthcare Professional Students, Downloaded from https://www.cambridge.org/core. IP address: 139.228.1.197, on 14 Feb 2019 at 18:50:10, subject to the Cambridge Core terms of use,. 